\title{
Integrated Optimization of the Location-Inventory Problem of Maintenance Component Distribution for High-Speed Railway Operations
}

\author{
Dezhi Zhang ${ }^{1}$, Shuxin Yang ${ }^{1}$, Shuangyan $\mathrm{Li}^{2}$, Jiajun Fan ${ }^{1}$ and Bin Ji ${ }^{1, *}$ \\ 1 School of Traffic and Transportation Engineering, Central South University, Changsha 410075, China; \\ dzzhang@csu.edu.cn (D.Z.); YangShuXin@csu.edu.cn (S.Y.); fanjiajun@csu.edu.cn (J.F.) \\ 2 College of Logistics and Transportation, Central South University of Forestry and Technology, \\ Changsha 410004, China; t20050768@csuft.edu.cn \\ * Correspondence: chcujibin@csu.edu.cn; Tel.: +86-(0)-731-82655326
}

Received: 11 May 2020; Accepted: 30 June 2020; Published: 6 July 2020

\begin{abstract}
Sustainable distribution network design for the maintenance components of electric multiple units (EMUs) is critical to reduce the problem of unreasonable resource allocation and capital occupation of high-speed railway (HSR) operations. Motivated by the above analysis, this study investigates the integrated optimization of the location and inventory of EMU maintenance component distributions. Aiming to improve the sustainable operation for high-speed railway, we proposed a corresponding nonlinear mixed-integer programming model to determine the location of the distribution center (DC) for EMU maintenance component delivery, inventory control strategy, and corresponding service level. The above optimization model is solved by an adaptive improved genetic algorithm. The proposed model and algorithm are applied to a real-world case study on China's EMU maintenance components. The findings show that a higher service level is not better to achieve the lower total cost in the maintenance component distribution network. The ratios of transportation modes are significant to balance the service level and total cost of the EMU distribution network. Furthermore, the unit out-of-stock cost and the service level both show great impacts on the total costs of the EMU distribution system. Finally, there exists an optimal ratio of different transport modes, which ensures the least total cost of the EMU distribution system.
\end{abstract}

Keywords: distribution network design; maintenance components of high-speed railway; location-inventory problem; optimization model; adaptive genetic algorithm; case study

\section{Introduction}

As a new method of transportation, high-speed railways have attracted extensive attention in recent years. By the end of 2019, China had built a high-speed rail system of 35,000 km, which is more than $2 / 3$ of the total length of all global high-speed rail systems [1,2]. Along with the construction of high-speed rail networks, the demand for electronic multiple unit (EMU) trains is increasingly strong. For example, as of early 2019, the China Railway Administration owned 2827 EMU trains, an increase of $11.3 \%$ year-on-year. The first high-speed line was the Beijing-Tianjin high-speed rail line, which was put into operation in 2008 [3]. According to the maintenance standards, the upcoming maintenance period will be a problem for a considerable number of EMU trains. The long-term plan for high-speed railway networks and the current macroeconomic background raise concerns for scholars and managers regarding the distribution network design of maintenance components for high-speed railway operation.

Inevitably, the construction of the distribution network for EMU maintenance components involves the distribution network design, the distribution transportation mode, and the corresponding inventory 
strategies, which are important issues for integrated optimization. "Safety first" is an important feature of the traditional inventory management of maintenance components. That is, to cope with the shortage of stock each EMU depot store requires many maintenance components for the monthly plan. However, this arrangement not only causes inefficient use of components but also leads to high holding costs [4]. In addition, the maintenance method of the EMU train is different from that of the conventional train. It is divided into one to five levels of maintenance. Taking the EMU powder metallurgy brake as an example, it belongs to the third level maintenance. The consumption of this brake is subject to mileage, which increases the uncertainty of the corresponding demand. Furthermore, the price of EMU train maintenance components is much more expensive, and they need to keep a rational level inventory based on the principle of "safety first," which usually incurs a slightly higher inventory cost. The China Railway Administration might increase costs by maintaining an excess inventory of maintenance components. In contrast, insufficient inventory reduces service levels and incurs unnecessary transportation costs due to urgent orders. For example, maintenance components that are usually transported by road have to be transported by air because of time constraints, which may yield economic losses. Therefore, the China Railway Administration wants to make strategic and tactical decisions simultaneously.

In summary, this paper aims to minimize the total cost of the location-inventory problem of maintenance component distribution for high-speed railway operations. Our proposed problem involves determining the optimal locations of distribution centers (DCs) of EMU components and the corresponding inventory control strategies (i.e., reorder points and optimal service level) based on the actual consumption and storage of maintenance components. Finally, combined with the distribution center location, this study integrates the scattered EMU maintenance component resources. It establishes regional integration and chooses the appropriate transportation modes and proportion of different transportation modes to ensure that the maintenance components are kept at a reasonable level and supplied in a timely manner when the corresponding demand is required. As an extension of the facility location problem, the location-inventory problem has proved to be a NP-hard problem. A genetic algorithm (GA) is an effective method to solve the above problem. It simulates the principle of survival of the fittest in nature, and through implicit parallel search, reduces the possibility of falling into a local optimal solution.

The rest of this paper can be summarized as follows. Section 2 reviews the literature on the location-inventory problem and proposes research gaps. Section 3 describes the problem and gives the modeling process. Section 4 presents an improved adaptive genetic algorithm. Section 5 applies the proposed algorithm to a real-world study and obtains some management insights and tactical decisions simultaneously. Conclusions are drawn and future work is discussed in Section 6.

\section{Literature Review}

The relevant research can be divided into three topics: (i) facility location problem, (ii) logistics network design, and (iii) location-inventory problem.

The distribution network configuration substantially influences strategic and tactical decisions. Traditionally, strategic and tactical decisions are made separately at different levels of management. Strategic decisions include considering the facility location and customer assignments [5]. Tactical decisions include inventory management and inventory control strategies. Owen and Daskin [6] were among the first scholars to study the facility location problem (FLP), and subsequent scholars have expanded a series of qualitative or quantitative models [7-11]. A great number of scholars have proposed different types of constraints to address industrial FLPs [12-14]. Shen [15] considered the multicommodity flow problem, Meraklı and Yaman [16] improved the capacitated hub location problem, and Correia et al. [17] solved a stochastic multiperiod capacitated multiple allocation hub location problem. Alumur et al. [18] presented a modeling for hub location problems with a service time limit considering congestion at hubs. Binary optimization of the FLP is a NP-hard problem, and there are various methods to solve it. Classical solution methods include column generation 
algorithms, branch and bound methods, benders decomposition, Lagrangian relaxation, and dynamic programming [7,19-21]. In recent years, an increasing number of scholars have used heuristic algorithms, including genetic algorithms, tabu search algorithms, simulated annealing algorithms, particle swarm optimization, and scatter search algorithms [8,22]. For solving nonlinear large-scale problems, heuristic algorithms are regularly used. The heuristic algorithm has the advantages of simple operation and fast solution speed under complex conditions. This paper considers a two-echelon distribution network of large scale, and the solution requires the use of a heuristic algorithm.

The logistics network design is different from the FLP, which usually includes multiple echelons and determines the number and capacity of facilities and the product flow in the entire network [23]. In recent years, the high-speed rail network has gradually improved, and the choice of transportation methods has also changed, including highways, railways, and airways [2]. Multimodal transport has become a research focus [24,25]. Different product flows with different transportation modes will produce different location allocation results, and finding a suitable transportation method is the research goal of this paper.

In addition to uncertain transportation options, factors such as uncertain customer demand exist [26,27]. Nickel et al. [28] investigated the problem of choosing the location and number of ambulances for minimum cost under stochastic demand. As for distribution network design, uncertain demand brings the need for safety stocks and the possibility of stockouts. This requires reasonable stock and service levels to avoid a large amount of capital occupation or losses caused by stockouts [29]. Singh et al. [30] provided an overview of inventory management in the logistics network design, clearly considering the importance of service level. Miranda and Garrido [31] adopted a sequential heuristic approach, a two-step formulation, to address the distribution network design problem and optimize inventory service levels. In the first step, the approach determined the optimal service level, and in the second step, it optimized the facility location and inventory strategy decisions. This paper focuses on different service levels and finds the relationship between service level, total cost, and transportation mode.

With the development of supply chain management, the location-inventory problem (LIP) has become a further expansion of the facility location problem and logistics network design, which makes simultaneous decisions on strategies and tactics [32]. Daskin et al. [33] formulated a model and proposed a solution method for the LIP. Shen et al. [34], combining real cases of local blood banks, established a location-inventory joint optimization model and used the risk-pooling principle to reduce safety stocks. The LIP has generated great interest in academia regarding a variety of situations, such as vendor-managed inventory, replenishment strategies, stochastic capacity, multi-period, and service constraint $[17,35-38]$. Some scholars integrated location, inventory, and routing problems in the supply chain network design, which are all NP-hard problems. Jahangir et al. [39] compared the performance of genetic and discrete invasive weed optimization (DIWO) algorithms for solving the inventory routing problem. They proved that a GA is better than DIWO to solve large-scale problems. Liu et al. [40] considered random supply disruptions and dealt with a coordinated location-inventory problem in a stochastic supply chain system. They addressed a tailored hybrid genetic algorithm embedded with direct search. Many researchers have used genetic algorithms in solving such problems, which shows that a genetic algorithm is suitable to solve the location-inventory problem [41,42].

Compared with academia, the application of the LIP is a recent trend [43-45]. Farahani et al. [46] conducted a comprehensive review of the existing literature on LIPs and pointed out that there are a few studies combined with real-world situations. Therein, Manatkar et al. [47] proposed a model of the location-inventory problem considering multiple products in a multilevel supply chain for steel retailers to make decisions. Lin et al. [4] presented a mixed integrated formulation to obtain optimal inventory strategies and modes of transport for high-speed train maintenance components between the advance and the temporary order policy. The Program Evaluation and Review Technique (PERT) method was applied to deal with the shortage cost. However, our proposed problem differs from Lin et al. [4] in the following aspects. First, we extended the problem into a three-level network 
design. Moreover, our proposed problem aims to determine the optimal location selection of EMU maintenance component DCs and the combined transport modes, and considers also the stock shortage costs related to the corresponding service levels. Finally, our research findings show the relationship between the optimal service level and ratios of different transportation modes.

Finally, some features of related studies with the location-inventory problem are illustrated in Table 1.

Table 1. Review of the existing literature.

\begin{tabular}{|c|c|c|c|c|c|c|c|c|}
\hline \multirow[b]{2}{*}{$\begin{array}{l}\text { Reference Article } \\
\text { (Year) }\end{array}$} & \multicolumn{5}{|c|}{ Objective } & \multicolumn{2}{|c|}{$\begin{array}{c}\text { Transportation } \\
\text { Mode }\end{array}$} & \multirow[t]{2}{*}{$\begin{array}{c}\text { Solution } \\
\text { Procedure }\end{array}$} \\
\hline & $\begin{array}{l}\text { Location } \\
\text { Cost }\end{array}$ & $\begin{array}{c}\text { Transportation } \\
\text { Cost }\end{array}$ & $\begin{array}{c}\text { Ordering } \\
\text { Cost }\end{array}$ & $\begin{array}{l}\text { Holding } \\
\text { Cost }\end{array}$ & $\begin{array}{c}\text { Penalty } \\
\text { Cost }\end{array}$ & Single & Multiple & \\
\hline Zhang et al. [32] & . & . & . & . & & & . & Lingo \\
\hline Vahdani et al. [45] & . & . & & . & . & . & & $\begin{array}{l}\text { Heuristic } \\
\text { Algorithm }\end{array}$ \\
\hline Shahabi et al. [48] & . & . & & . & & . & & $\begin{array}{l}\text { Heuristic } \\
\text { Algorithm }\end{array}$ \\
\hline $\begin{array}{l}\text { Ahmadi-Javid, } \\
\text { Amir and } \\
\text { Hoseinpour, } \\
\text { Pooya [49] }\end{array}$ & . & . & $\cdot$ & $\cdot$ & & $\cdot$ & & $\begin{array}{l}\text { Heuristic } \\
\text { Algorithm }\end{array}$ \\
\hline This research & . & . & . & . & . & & . & $\begin{array}{l}\text { Heuristic } \\
\text { Algorithm }\end{array}$ \\
\hline
\end{tabular}

Thus, the main contributions of this paper to filling the research gap are as follows: (i) to construct a joint optimization model for the LIP considering multimodal transport and to minimize the cost of fixed operating, inventory, transportation, and stockout penalties. (ii) Because comprehensive location-inventory decisions are more complicated than individual decisions, we propose an improved adaptive genetic algorithm using matrix encoding. In addition, an efficient genetic operator is designed to address the model. (iii) According to the actual background of a high-speed railway, the model provides the foundation and strategy for solving the optimization problem of the EMU maintenance component distribution network.

\section{Problem Description and Modeling Process}

This paper focuses on a location-inventory model based on real situations. The China Railway Administration, as a company with a social welfare focus, must consider safe public travel. Thus, the distribution network needs to ensure the timely supply of EMU maintenance components. Otherwise, large-scale high-speed train outages and even social unrest may occur. Based on this characteristic, we added penalty costs, which are out-of-stock costs, into the location inventory formulation that distinguishes maintenance components of the EMU distribution network from regular components.

\subsection{Problem Description}

The considered three-layer distribution network is shown in Figure 1. It consists of multiple suppliers, potential distribution centers, and EMU depots. This problem aims to minimize the total cost of distribution network design. Location is a high initial investment and has long-term impact. Furthermore, inventory policy selection is imperative. Due to stochastic demand, determining inventory policy can solve problems such as how often to reorder, the economic order quantity (EOQ), and the level of safety stock to establish. It is significant to deal with the trade-off between the safety stock and the corresponding service level in supply chain management. To set a lower level of safety stocks will result in decreasing of the service levels and increasing of the corresponding penalty cost. On the contrary, the higher the safety stock, the higher the ratio of meeting the demand with uncertainty and the higher the service level. However, high safety stock will cause high capital occupancy, as well as the lower ratio of turnover of EMU components. Finally, it is important to choose transport 
modes. As we all know, different modes of transportation have different advantages. Air freight is efficient and fast but is greatly affected by weather. High-speed rail transport makes up for this shortcoming but is still in its infancy. The road transport cost is the smallest compared to that of the previous two modes, but the timeliness is poor. This study never considers the cost in transit, which distinguishes the advantages of different transportation modes by order cost and transportation cost. Therefore, their impact on the service level can be reflected in two aspects: the fixed order cost and the transportation cost. So, it is necessary to choose an optimal combined transport service scheme to reduce the total cost of the maintenance component distribution system.

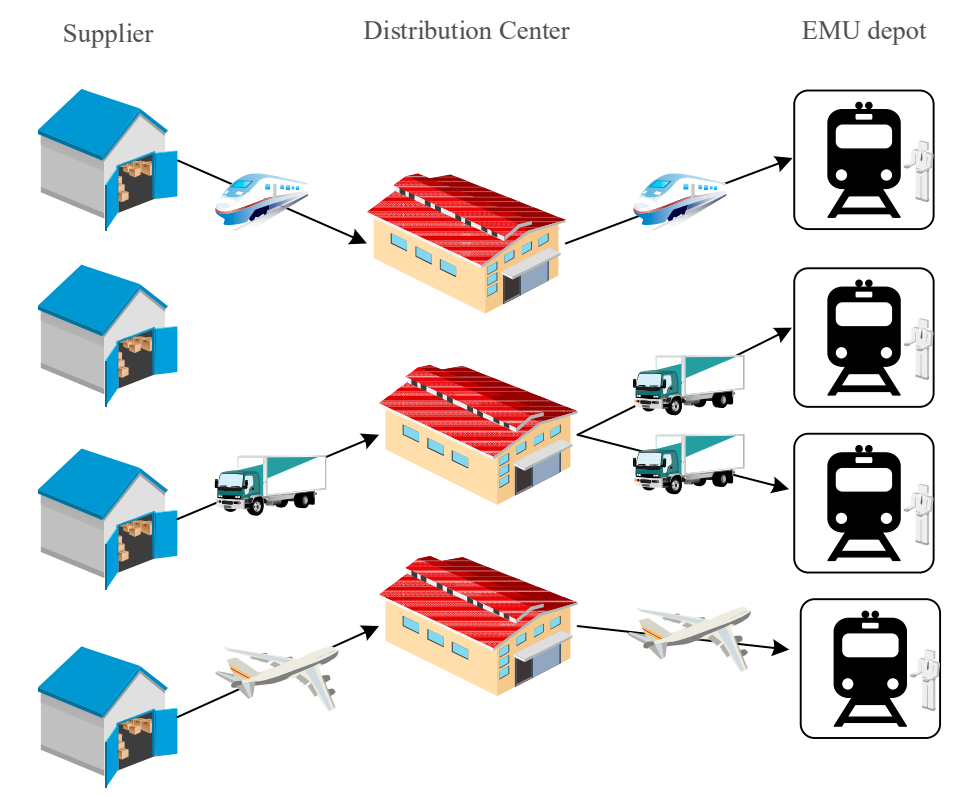

Figure 1. Three-layer distribution network. EMU: electronic multiple unit.

In summary, our model aims to minimize the total cost, which is the sum of the location cost, transportation cost, inventory cost, and penalty cost. The inventory cost in the model includes the fixed ordering, the holding cost of the cycle, and the safety stock in the distribution center. Through this mixed-integer nonlinear programming model of location inventory, we can finally determine (i) the facility location and number of distribution centers; (ii) the allocation plan from the suppliers to distribution centers and distribution centers to EMU depots, and the choice of transportation mode; and (iii) the distribution center economic order quantity, reorder point, and safety stock.

\subsection{Assumptions and Notations}

The study makes the following assumptions:

(i) Every distribution center has a fixed construction cost;

(ii) Normal distributions of known mean and variance are followed by the maintenance component demand of each EMU depot. There are independent demands for different EMU depots;

(iii) There is only one supplier per distribution center and only one distribution center per EMU depot;

(iv) Each distribution center adopts a continuous review $(r, Q)$, which means that when the inventory level falls below the reorder point $r$, each distribution center orders a fixed quantity $Q$ at once;

(v) The unit transportation cost is proportional to distance and product shipment.

The model sets, parameters, decision variables, and intermediate variables used throughout the paper are listed as follows:

Indices: 
I: Index for EMU depots, $i=1,2, \ldots I$

$J$ : Index for potential distribution center locations, $j=1,2, \ldots J$

$K$ : Index for suppliers, $k=1,2, \ldots K$

$T$ : Index for mode of transport, $t=1,2, \ldots T$

Parameters:

$f_{j}$ : Fixed operating cost of opening a distribution center $j$ per unit time ( $\left.¥\right)$

$C_{t}$ : Unit transportation cost by transport mode $t(\because /$ unit $\cdot \mathrm{km}$ )

$T_{k j}$ : The distance from supplier $k$ to distribution center $j(\mathrm{~km})$

$S_{j i}:$ The distance from distribution center $j$ to EMU depot $i(\mathrm{~km})$

$\mu_{i}$ : Mean daily demand at EMU depot $i$ (unit)

$\sigma_{i}^{2}$ : Variance of daily demand at EMU depot $i\left(\right.$ unit $\left.^{2}\right)$

$\chi$ : Days worked in a year (day)

$L T_{j}$ : Lead time of the distribution center $j$ to order from supplier $k$ (day)

$O C_{j}^{t}$ : Fixed ordering cost at distribution center $j$ by transport mode $t$ ( $¥ /$ order)

$H C_{j}$ : Holding cost at distribution center $j$ ( $¥ /$ unit)

$S C_{j}$ : Shortage cost at distribution center $j$ ( $¥ /$ unit)

$\alpha_{j}$ : Service level for distribution center $j$

$Z_{\alpha}$ : Safety factor related to service level and standard normal distribution, $P\left(Z \leq Z_{\alpha}\right) \leq \alpha$

Intermediate Variables:

$D_{j}$ : Mean of daily demand allocated to potential distribution center $j$ (unit)

$V_{j}^{2}$ : Variance of daily demand allocated to potential distribution center $j\left(\mathrm{unit}^{2}\right)$

$Q_{j}$ : Optimal order quantity for distribution center $j$ (unit)

$r_{j}$ : Reorder point for distribution center $j$ (unit)

Decision Variables:

$X_{j} \in\{0,1\}$, Takes the value 1 when located at distribution center $j$; otherwise, the value 0 ;

$Y_{k j}^{t} \in\{0,1\}$, Takes the value 1 when distribution center $j$ is allocated to supplier $k$ by transport mode $t$; otherwise, the value 0 ;

$Z_{j i}^{t} \in\{0,1\}$, Takes the value 1 when EMU depot $i$ is allocated to distribution center $j$ by transport mode $t$; otherwise, the value 0 .

\subsection{Location-Inventory Model}

The location-inventory problem of the maintenance components was formulated as a mixed-integer nonlinear programming model. The objective function of the model was to minimize the total cost, including the fixed operating cost, transportation cost, inventory cost, and penalty cost as follows:

(1) The fixed operating cost of opening distribution centers, given as $\sum_{j} f_{j} X_{j}$;

(2) The transportation cost from the supplier to the opened distribution center, given by $\sum_{k} \sum_{j} \sum_{t}\left(C_{t} T_{k j} \chi \mu_{i} Z_{j i}^{t} Y_{k j}^{t}\right)$, and from the opened distribution center to the EMU depot, given by $\sum_{j} \sum_{i} \sum_{t}\left(C_{t} S_{j i} \chi \mu_{i} Z_{j i}^{t}\right)$. We assume that the transportation cost is related to maintenance component shipment, transportation distance, and transport mode;

(3) The inventory cost includes the ordering cost, the holding cost of working inventory and safety stock. The mean of daily demand at EMU depot $i$ follows a normal distribution with $N\left(\mu_{i}, \sigma_{i}{ }^{2}\right)$. Because of unrelated demand, the mean of daily demand at distribution center $j$ also obeys the normal distribution with $N\left(D_{j}, V_{j}^{2}\right)$, where $D_{j}=\sum_{i} \sum_{t} \mu_{i} Z_{j i}^{t}, \forall j$, and $V_{j}^{2}=\sum_{i} \sum_{t} \sigma_{i}^{2} Z_{j i}^{t}, \forall j$. To facilitate the model solution, Shen et al. [34] proposed approximating the demand of a normal distribution by a Poisson distribution. It is common to assume that $\sigma_{i}^{2} / \mu_{i}=\gamma, \forall i$, where $\gamma$ is the ratio of variance and mean. Based on this assumption, safety stock can be obtained as $s s_{j}=Z_{\alpha} \sqrt{\gamma D_{j} L T_{j}}, \forall j$, and the reorder point is $r_{j}=D_{j} L T_{j}+Z_{\alpha} \sqrt{\gamma D_{j} L T_{j}}, \forall j$; 
(4) For each distribution center $j$, we set the penalty cost caused by stock shortages. Miranda and Garrido [31] assumed a normal demand distribution for stochastic demand during lead time, $S D_{j}\left(L T_{j}\right)$, and the density function of $S D_{j}\left(L T_{j}\right)$ is computed by (1):

$$
f(x)=\frac{1}{\sqrt{2 \pi} \sqrt{V_{j}^{2} L T_{j}}} e^{-(1 / 2)\left(x-D_{j} L T_{j} / \sqrt{V_{j}^{2} L T_{j}}\right)^{2}}=\frac{1}{\sqrt{2 \pi} \sqrt{\gamma D_{j} L T_{j}}} e^{-(1 / 2)\left(x-D_{j} L T_{j} / \sqrt{\gamma D_{j} L T_{j}}\right)^{2}} .
$$

Expected out-of-stock demand is given by (2).

$$
\int_{r_{j}}^{+\infty}\left(x-r_{j}\right) f(x) d x=\int_{r_{j}}^{+\infty} x f(x) d x-r_{j} \int_{r_{j}}^{+\infty} f(x) d x
$$

where

$$
\int_{r_{j}}^{+\infty} x f(x) d x=\frac{\sqrt{\gamma D_{j} L T_{j}}}{\sqrt{2 \pi}} e^{-(1 / 2) Z_{\alpha}^{2}}+D_{j} L T_{j}\left(1-\alpha_{j}\right)
$$

and

$$
\int_{r_{j}}^{+\infty} f(x) d x=1-\alpha_{j}
$$

The penalty cost for a distribution center $j$ in a single ordering period can be obtained by (5).

$$
S C_{j}\left[\frac{1}{\sqrt{2 \pi}} e^{-(1 / 2) Z_{\alpha}^{2}}-\left(1-\alpha_{j}\right) Z_{\alpha}\right] \sqrt{\gamma D_{j} L T_{j}} .
$$

In short, the inventory and penalty cost of the distribution center $j$ can be expressed by (6), where $\chi D_{j} / Q_{j}$ is the expected order frequency in a year.

$$
I C_{j}+P C_{j}=O C_{j}^{t} \frac{\chi D_{j}}{Q_{j}}+H C_{j}\left(\frac{Q_{j}}{2}+s s_{j}\right)+S C_{j}\left[\frac{1}{\sqrt{2 \pi}} e^{-(1 / 2) Z_{\alpha}^{2}}-\left(1-\alpha_{j}\right) Z_{\alpha}\right] \sqrt{\gamma D_{j} L T_{j}} \frac{\chi D_{j}}{Q_{j}} \forall j, t .
$$

The first term of (6) is the fixed ordering cost, the second term represents the holding cost with working inventory and safety stock, and the third term expresses the out-of-stock penalty cost.

Consistent with $[31,33]$, this paper assumes that the EOQ model determines the optimal order quantity of each distribution center $j, Q_{j}=\sqrt{2 O C_{j}^{t} \chi D_{j} / H C_{j}}$.

Thus, the inventory and penalty cost for each distribution center $j$ can be rearranged by (7).

$$
I C_{j}+P C_{j}=\sqrt{2 \chi H C_{j} O C_{j}^{t} D_{j}}+H C_{j} Z_{\alpha} \sqrt{\gamma L T_{j} D_{j}}+S C_{j} D_{j}\left(\frac{1}{\sqrt{2 \pi}} e^{-\frac{1}{2} Z_{\alpha}^{2}}-\left(1-\alpha_{j}\right) Z_{\alpha}\right) \sqrt{\frac{\gamma \chi L T_{j} H C_{j}}{2 O C_{j}^{t}}}, \forall j .
$$

Extracting the constant term in (7), the inventory cost and penalty cost can be rewritten by (8) and (9), respectively.

$$
\begin{gathered}
I C_{j}=\lambda_{1 j} \sqrt{D_{j}}, \forall j, \\
P C_{j}=\lambda_{2 j} D_{j}, \forall j,
\end{gathered}
$$

where $\lambda_{1 j}=\sqrt{2 \chi H C_{j} O C_{j}^{t}}+H C_{j} Z_{\alpha} \sqrt{\gamma L T_{j}}, \lambda_{2 j}=S C_{j}\left(\frac{1}{\sqrt{2 \pi}} e^{-\frac{1}{2} Z_{\alpha}^{2}}-\left(1-\alpha_{j}\right) Z_{\alpha}\right) \sqrt{\frac{\gamma \chi L T_{j} H C_{j}}{2 O C_{j}^{t}}}$.

The service level determines the safety stock on the one hand, and is related to the stock shortage on the other hand. Penalty costs are incurred due to out-of-stock inventory, which shows great impact on the total cost of the entire distribution system because the China Railway Administration should 
meet the requirement of EMU maintenance component supply in a timely manner, so as to provide a strong guarantee for on-time operation of high-speed train operators.

As described above, this paper analyzes the inventory cost of the distribution center $j$; thus, we propose a location-inventory model for the optimization of the distribution network of the EMU maintenance components. The model is formulated as follows (10)-(17):

$$
\begin{gathered}
\operatorname{Min} \sum_{j} f_{j} X_{j}+\sum_{j} \lambda_{1 j} \sqrt{D_{j}}+\sum_{j} \lambda_{2 j} D_{j}+\sum_{k} \sum_{j} \sum_{t}\left(C_{t} T_{k j} \chi \mu_{i} Z_{j i}^{t} Y_{k j}^{t}\right)+\sum_{j} \sum_{i} \sum_{t}\left(C_{t} S_{j i} \chi \mu_{i} Z_{j i}^{t}\right), \\
\sum_{k} \sum_{t} Y_{k j}^{t} \leq X_{j}, \forall j, \\
\sum_{j} \sum_{t} Z_{j i}^{t}=1, \forall i, \\
Z_{j i}^{t} \leq X_{j}, \forall j, i, t, \\
\sum_{t} Y_{k j}^{t} \leq 1, \forall k, j, \\
\sum_{t} Z_{j i}^{t} \leq 1, \forall j, i, \\
D_{j}=\sum_{i} \sum_{t} \mu_{i} Z_{j i}^{t}, \forall j, \\
X_{j}, Y_{k j}^{t}, Z_{j i}^{t} \in\{0,1\}, \forall i, j, k, t .
\end{gathered}
$$

The objective function (10) minimizes the total cost of the distribution network for EMU maintenance components and warrants further explanation. The first term is the fixed cost of opening a DC to operate at site $j$. The second term indicates the inventory cost at the opening DCs, which includes fixed ordering cost, holding cost of the cycle and the safety stock for each DC. The third term is the penalty cost of stockout. The last two terms represent the transportation cost from supplier $k$ to opening DC $j$ and from opening DC $j$ to EMU depot $i$.

Constraints (11) state that a DC is only serviced by a supplier; constraints (12) show that each EMU depot is only serviced by a DC. Constraints (13) stipulate that the DC-serviced EMU depots are open. Constraints (14) and (15) ensure that the maintenance component can only use one transport mode in transit. Constraints (16) compute the mean daily demand for each open DC. The domains of the decision variables are defined in constraints (17).

\section{Adaptive Genetic Algorithm}

Heuristic algorithms are the most appropriate approaches that are used to solve the proposed mixed-integer nonlinear programming (MINLP). There are some classical heuristic methods, such as simulated annealing (SA), tabu search (TS), and genetic algorithm (GA). Each algorithm has its own strengths and weaknesses. GA, based on survival of the fittest and population genetics, is the most widely used in optimal NP-hard problems. Since the LIP is essentially an NP-hard problem, this paper adopted a GA to solve it. Starting from a set of feasible solutions, a GA finds better solutions by simulating the mechanism of selections and genetics in the natural world, such as crossover and mutation processes, and evolves according to the regulation of nature-survival of the fittest. The GA encodes the problem parameters into genes in the chromosome for optimization, and the resolution process starts with a population rather than an individual. Thus, one of the best features of a GA is that with implicit parallel search, the possibility of falling into a local optimal solution is reduced. Therefore, in this paper, we chose the GA to solve this INLP because of its performance in parallel search and avoiding location-optimal solutions. 
However, undesirable effects and low efficiency are always found when using a GA to solve the LIP because of the initial solution, imperfect coding of chromosomes, and inappropriate crossover and mutation rates. In our adaptive genetic algorithm, we randomly generated the initial solution and adopted multi-matrix coding of chromosomes to improve the speed and enhance the legitimacy of the chromosomes to reduce the probability of illegal solution.

\subsection{Chromosome Representation}

In GAs, the conversion method that converts the feasible solution of a problem from a model variable to the search space that the GA can handle is called coding. The encoding and decoding of chromosomes determine the rate of solution. In this paper, the decision variables of the proposed model consist of three binary variables, and two vectors and four matrices make up the code for each chromosome. To facilitate the description of the encoding and decoding process, Figure 2 is presented with the scale of the three suppliers, five distribution centers, and five EMU depots. The two vectors represent the binary allocation decisions of the supplier-distribution center and distribution center-EMU depot. The four matrices represent the economic order quantity between suppliers and distribution centers (S-DC Quantity), the transport mode between suppliers and distribution centers (S-DC Transport mode), the economic order quantity between distribution center and EMU depot (DC-E Quantity), and the transport mode (DC-E Transport mode). A visual description of these matrices is shown in Figure 2; the former number represents quantity and the latter number represents transport mode. The rows and columns of each matrix are determined by suppliers, distribution centers, or EMU depots. The volume of EMU maintenance components is a real number, and the mode of transportation is considered only as an integer.
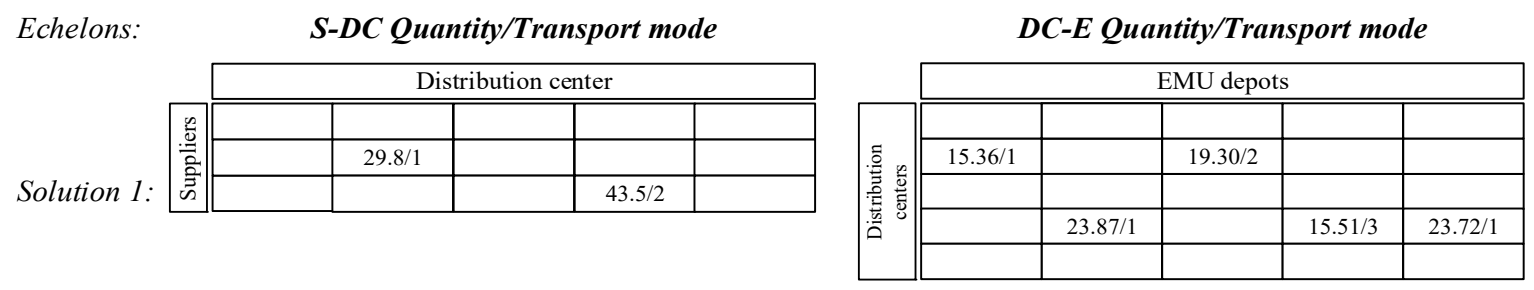

Figure 2. Representation of chromosomes.

First, under the condition that an EMU depot is only serviced by one distribution center, the distribution center randomly serves the EMU depots in the DC-E echelons and repeats this allocation process until the demand of each EMU depot is assigned and the relevant transport modes are selected.

Subsequently, in the S-DC echelons, the similar allocation procedure between suppliers and distribution centers is repeated, and the volume of EMU maintenance components is the total demand of each EMU depot serviced by the open distribution center. In this echelon, the supplier-serviced open distribution center and the corresponding transport flows and transportation modes are determined.

This form of representation facilitates the manipulation, search, and expression of chromosomes in the evolutionary process.

\subsection{Genetic Operator}

Genetic operators are an important part of GAs, including selection, crossover, and mutation operators used to produce the offspring. To diversify the population, the three major operators were employed to select individuals with good fitness, crossover, or mutate in a current population with a certain probability. 


\subsubsection{Selection}

In this paper, we used a combination of roulette and optimal individual preservation to select excellent individuals from the population and eliminate individuals with low fitness. This combination selection strategy can inherit the contemporary optimal individual into the next generation population. In this way, we could avoid the influence of crossover or mutation on its chromosome structure, while the remaining individuals who survive as the fittest are determined by roulette to enter the next generation. This method can not only make the individual generation of the largest fitness in the population better than the first generation but also ensure the individual diversity in the population and choose whether to inherit the next generation according to the ratio of the fitness function value.

The roulette operator is also called the proportional selection operator, assuming that $\sum_{u} f_{u}$ is the sum of the fitness function values of a certain population, and $f_{u}$ is the fitness function value of the $u$ individual; then, $P_{u}$ is the probability that the individual is selected and their genes are passed to the next generation for (18):

$$
P_{u}=\frac{f_{u}}{\sum_{u} f_{u}}, u=1,2, \ldots, \text { popsize. }
$$

That is, the probability of selection and inheritance in the next generation is directly proportional to the individual fitness value. By simulating the roulette, the number of times each chromosome is present in the population is obtained, and the genetic purpose is achieved. Combined with the best individual preservation strategy, individuals with the largest fitness function value in the population can be directly copied to the next generation, and to ensure their superiority, they do not participate in crossover and mutation operations.

\subsubsection{Crossover}

In this paper, a partially matched crossover (PMX) was used to randomly select two intersections in a chromosome, thereby obtaining a partial matching region and then exchanging the region between two intersections in the parent to obtain two offspring chromosomes.

Step 1: Determine whether an individual has to crossover;

Step 2: Determine the crossover section;

Step 3: Determine the crossover position, namely, which columns to exchange;

Step 4: Modify the relationship between individual fragments. If there are sections that do not meet the condition, then reconstruct upstream, and the process is similar to the initial solution.

The crossover procedure is shown in detail in Figure 4.

\subsubsection{Mutation}

In this section, we used the method of interchange mutation to exchange new genes to obtain new chromosomes.

Step 1: Determine whether an individual has to mutate;

Step 2: Determine the mutated section;

Step 3: Determine the mutated position, namely, determine which lines to exchange;

Step 4: Modify the relationship between individual fragments. If there are sections that do not meet the condition, then reconstruct upstream, and the process is similar to the initial solution.

The mutation procedure is shown in detail in Figure 3. 
Echelons:

Parent \begin{tabular}{|c|c|c|c|c|c|}
\hline \multicolumn{1}{c|}{} & \multicolumn{5}{c|}{ Distribution centers } \\
\hline & & & & & \\
\hline
\end{tabular}

Echelons:

Child

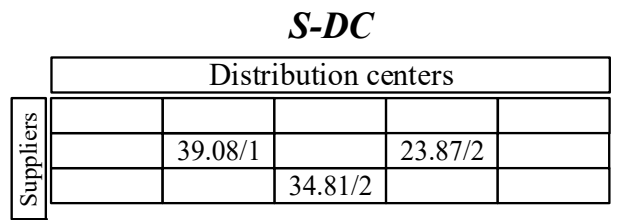

$D C-E$

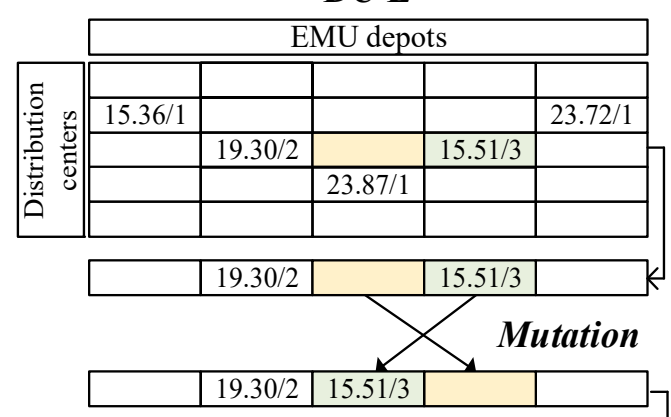

$D C-E$

\begin{tabular}{|c|c|c|c|c|c|}
\hline & \multicolumn{5}{|c|}{ EMU depots } \\
\hline \multirow{4}{*}{ 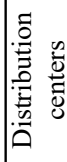 } & & & & & \\
\hline & $15.36 / 1$ & ${ }_{1030}$ & & & $23.72 / 1$ \\
\hline & & & & $23.87 / 1$ & \\
\hline & & & & & \\
\hline
\end{tabular}

Figure 3. Mutation process.

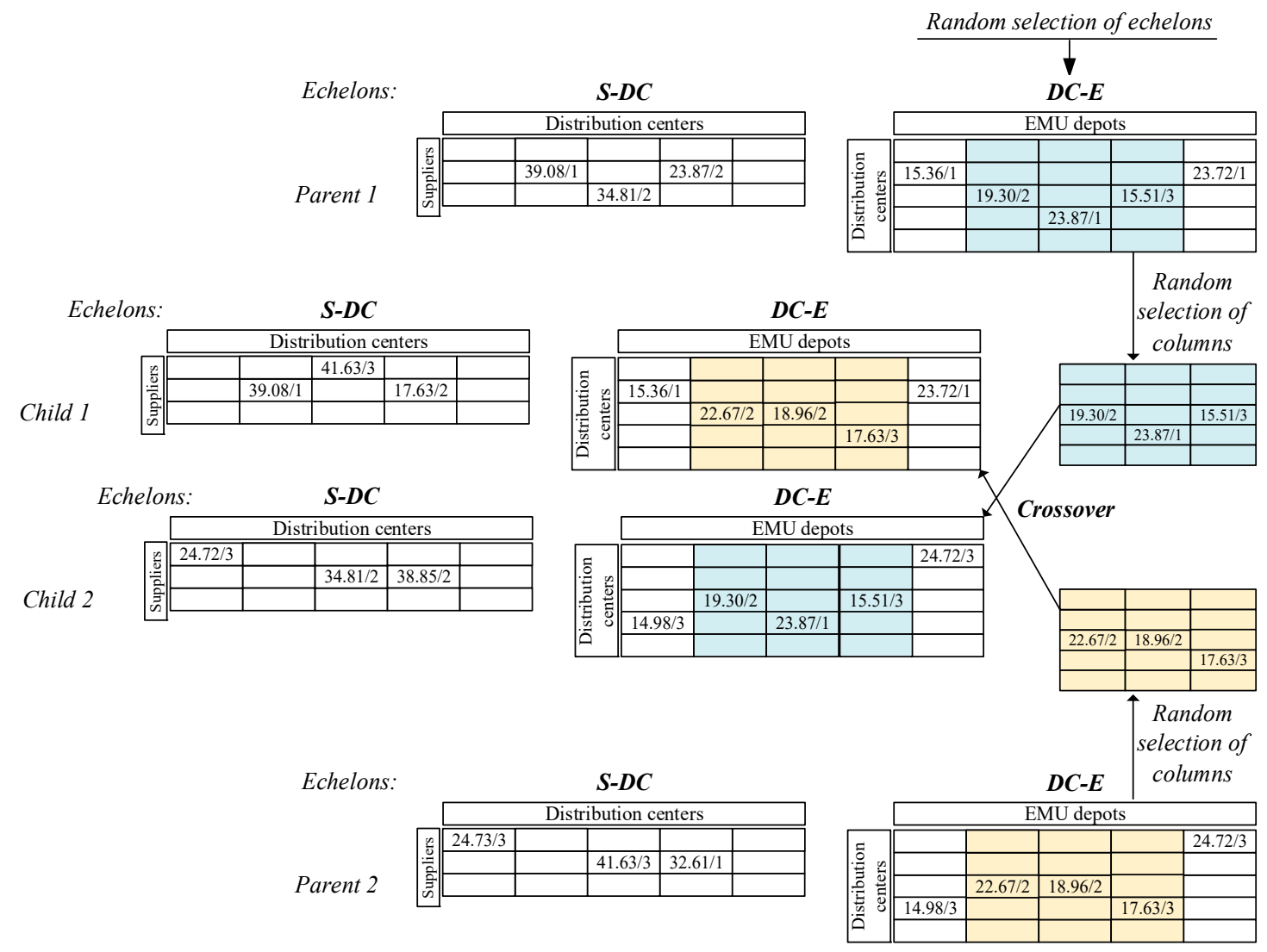

Figure 4. Crossover process.

\subsection{Adaptive Probabilities of Crossover and Mutation}

In the genetic algorithm, the choice of the crossover probability $P_{c}$ and the mutation probability $P_{m}$ will affect the performance and effectiveness of the algorithm. Unreasonable parameter selection may result in the algorithm not converging to the global optimum and falling into the local optimum. 
The traditional genetic algorithm presets the crossover and mutation probability to a specific value, which is calculated by the probability in the whole genetic process. When the iteration reaches a certain level, it is obviously unreasonable to cross or mutate with a certain probability. To affect the performance of the algorithm, Srinivas and Patnaik [50] proposed an adaptive genetic algorithm through a large number of experimental studies. In recent years, many scholars have improved the genetic probability and proposed different adaptive genetic algorithms. In this paper, the improved formulas for calculating the adaptive crossover ratio and mutation ratio are shown in (19) and (20):

$$
\begin{gathered}
P_{c}=\left\{\begin{array}{ll}
\frac{k_{1}\left(F_{a v g}-F^{\prime}\right)+k_{2}\left(F^{\prime}-F_{\min }\right)}{F_{a v v}-F_{\min }} & F^{\prime}<F_{a v g}, \\
\frac{k_{2}\left(F_{\max }-F^{\prime}\right)+k_{3}\left(F^{\prime}-F_{a v g}\right)}{F_{\max }-F_{a v g}} & F^{\prime} \geq F_{a v g}
\end{array},\right. \\
P_{m}= \begin{cases}\frac{k_{4}\left(F_{a v g}-F\right)+k_{5}\left(F-F_{\min }\right)}{F_{a v g}-F_{\min }} & F<F_{a v g} \\
\frac{k_{5}\left(F_{\max }-F\right)+k_{6}\left(F-F_{a v g}\right)}{F_{\max }-F_{a v g}} & F \geq F_{a v g}\end{cases}
\end{gathered}
$$

where $k_{1}, k_{2}, k_{3}, k_{4}, k_{5}$ and $k_{6}$ all lie in the interval $(0,1)$ and $k_{1}>k_{2}>k_{3}, k_{4}>k_{5}>k_{6} ; F$ represents the individual fitness value; $F_{\min }, F_{\max }$ and $F_{\text {avg }}$ represent the minimum, maximum, and average values of all the individual fitness functions in the contemporary population, respectively; and $F^{\prime}$ represents the larger individual fitness function value at the intersection of individual operations.

\subsection{Process of the Genetic Algorithm}

Based on the above description, we can conclude the main process of the adaptive genetic algorithm:

Step 1: Initialize parameters. Set the population size, encoding and decoding methods, and the maximum number of iterations of the genetic algorithm.

Step 2: Generate the initial population. Two vectors and four matrices are used to randomly generate the initial population and obtain the chromosomes in line with the population size.

Step 3: Obtain the fitness function value. The fitness function is used to calculate the fitness value $\mathrm{fu}, \mathrm{u}=1,2, \ldots$ popsize.

Step 4: Selection operation. The combination of elite strategy and roulette strategy is adopted to determine whether the individual performs the selection operator. If the elite strategy is satisfied, the individual will be directly inherited to the next generation without crossover or mutation; otherwise, roulette will decide whether to enter the next step or not.

Step 5: Crossover operation. Use the improved adaptive crossover probability formula to obtain the current crossover probability $P_{c}$ and compare it with the number generated randomly between $[0,1]$ to decide whether to perform the partial matching crossover operation.

Step 6: Mutation operation. Adopt the improved adaptive variation probability formula to obtain the current variation probability $P_{m}$ and compare it with the number generated randomly between $[0,1]$ to decide whether to perform the swap mutation operation.

Step 7: Termination. Determine whether the maximum number of population evolutions is satisfied. If so, the final solution is obtained; if not, return to Step 4.

The algorithm flow chart is shown in Figure 5. 


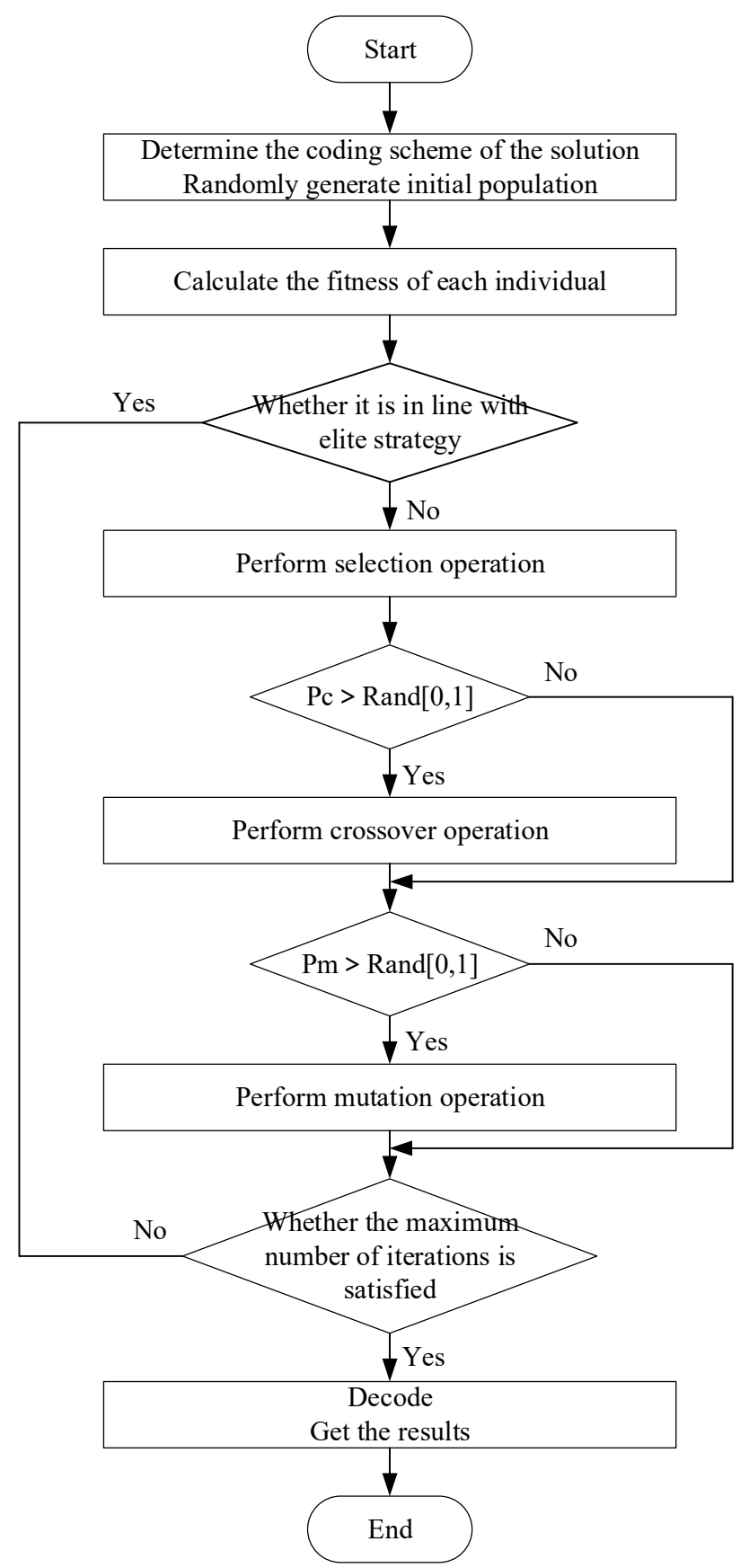

Figure 5. Adaptive genetic algorithm flowchart.

\section{Computational Implementations and Discussion}

\subsection{Computational Implementations}

In this section, we considered 52 EMU depots of the China Railway Administration as customers. Meanwhile, because the EMU maintenance component distribution center is usually built close to the EMU depot, 52 EMU depots were also regarded as distribution centers. Four suppliers provided the EMU maintenance components. The above optimal model of $n$ in Section 3.3 and the corresponding algorithm mentioned in Section 4 were applied to solve this two-echelon EMU components distribution network. The corresponding parameters are shown in Table 2. 
Table 2. Parameter value table.

\begin{tabular}{cll}
\hline Parameters & Description & $\begin{array}{c}\text { Range } \\
\text { [minimum, maximum] }\end{array}$ \\
\hline$f_{j}$ & Fixed operating cost of opening a distribution center $j(¥ 10,000)$ & {$[52.50,124.75]$} \\
$C_{t}$ & Unit transportation cost by transport mode $t ¥ 10,000 /$ kilometer $)$ & {$[0.00005,0.0003]$} \\
$T_{k j}$ & The distance from supplier $k$ to distribution center $j($ kilometer $)$ & {$[27.2,3858.4]$} \\
$S_{j i}$ & The distance from distribution center $j$ to EMU depot $i$ & {$[0,4709.9]$} \\
$\mu_{i}$ & (kilometer) & {$[2,43]$} \\
$\sigma_{i}^{2}$ & Mean of daily demand at EMU depot $i$ (unit) & {$[1.01,1.97]$} \\
$\chi$ & Variance of daily demand at EMU depot $i$ (unit $\left.{ }^{2}\right)$ & 365 \\
$L T_{j}$ & Days worked in a year $($ day) & {$[1,4]$} \\
$O C_{j}^{t}$ & Lead time for distribution center $j$ to order from supplier $k($ day) & {$[0.1,0.3]$} \\
$H C_{j}$ & Fixed ordering cost at distribution center $j$ by transport mode $t$ & 0.004 \\
$S C_{j}$ & (¥10,000/time) & 0.7 \\
$\alpha_{j}$ & Holding cost at distribution center $j(¥ 10,000 /$ day) & 0.9 \\
$Z_{\alpha}$ & Shortage cost at distribution center $j(¥ 10,000 /$ day) & 1.29 \\
\hline
\end{tabular}

To verify the effectiveness of the algorithm, we set six experiments with different sizes by standard genetic algorithms (SGAs) to compare with proposed adaptive genetic algorithms (AGAs). The basic parameter settings of the algorithm are shown in Table 3.

Table 3. Basic parameters of the algorithm.

\begin{tabular}{cccccc}
\hline Parameter & Value & Parameter & Value & Parameter & Value \\
\hline popsize & 200 & $k_{3}$ & 0.7 & $k_{6}$ & 0.01 \\
$k_{1}$ & 0.9 & $k_{4}$ & 0.05 & $P_{c}$ & 0.99 \\
$k_{2}$ & 0.8 & $k_{5}$ & 0.03 & $P_{m}$ & 0.1 \\
\hline
\end{tabular}

The computational tests were conducted on the MATLAB R2012a platform, the Intel (R) Core (TM) i5-8250U CPU @ 1.60 GHz CPU, 8.00 GB RAM, 64-bit operating system laptop.

Experiments were named as follows: S-DC-E, S, DC and E, representing the number of suppliers, distribution centers, and EMU depots, respectively. Because the EMU depots discussed in this paper were both distribution centers and themselves, the values of DC and E were the same. Comparing the SGA with the AGA, the following results were obtained.

Table 4 and Figure 6 show that when the scale was small, the results of the SGA and the AGA were relatively similar, but the larger the scale, the better the AGA was over the SGA. On the scale of 4-60-60, the difference between the AGA and the SGA was $969.32 \times ¥ 10,000$. Although the running time of the AGA was longer than that of the SGA, the difference was acceptable within $30 \mathrm{~s}$.

Table 4. Results of the SGA and the AGA.

\begin{tabular}{ccccc}
\hline \multirow{2}{*}{ Experiment } & \multicolumn{2}{c}{ SGA } & \multicolumn{2}{c}{ AGA } \\
\cline { 2 - 5 } & Total Cost & Running Time & Total Cost & Running Time \\
\hline $4-10-10$ & 370.03 & 21.80 & 238.88 & 26.22 \\
$4-20-20$ & 780.16 & 31.12 & 496.70 & 43.49 \\
$4-30-30$ & 1327.44 & 45.07 & 794.71 & 53.47 \\
$4-40-40$ & 1863.50 & 47.40 & 1121.57 & 56.37 \\
$4-50-50$ & 2257.70 & 57.18 & 1433.65 & 79.35 \\
$4-60-60$ & 2781.73 & 72.60 & 1812.41 & 86.81 \\
\hline
\end{tabular}




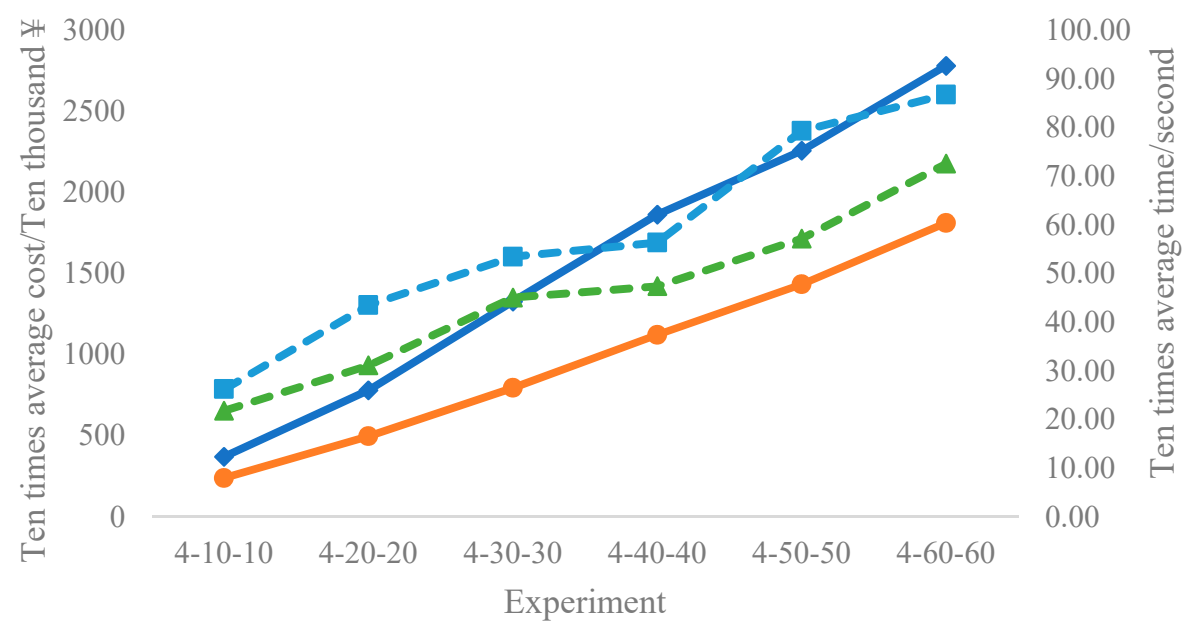

$\longrightarrow$ AGA cost $\longrightarrow$ SGA cost $\longrightarrow$ - AGA time $\quad$ - SGA time

Figure 6. Results of the standard genetic algorithm (SGA) and the adaptive genetic algorithm (AGA).

The geographical locations of four suppliers and 52 EMU depots are shown in Figure 7. The figure also shows the allocation and transportation modes from supplier to distribution center and distribution center to EMU depots. Assume that transportation modes 1 to 3 are air, high-speed rail, and road transportation, respectively.

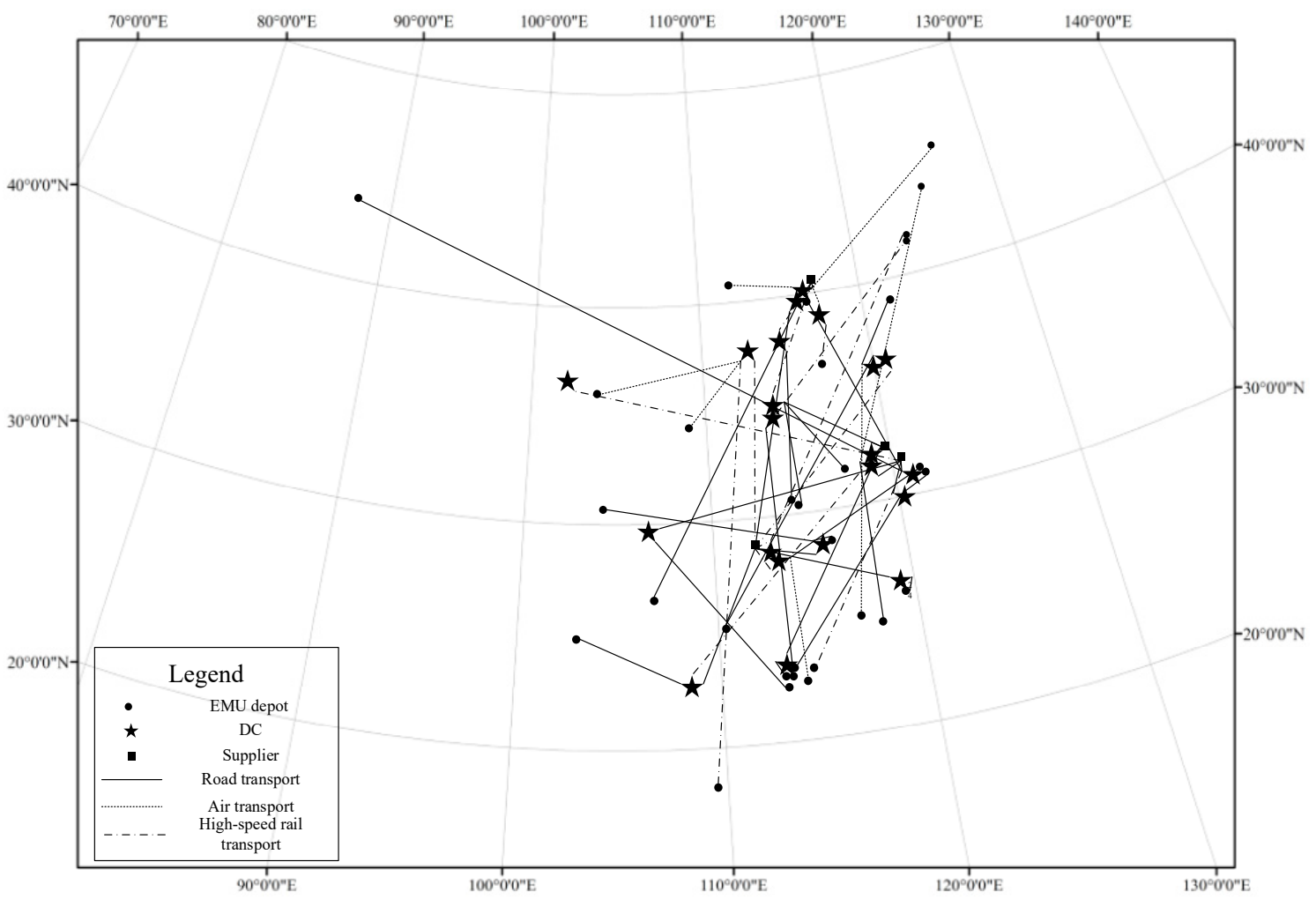

Figure 7. Geographical locations of computational implementation.

In the actual study, there were four suppliers and 52 EMU depots. Four suppliers: Tianyi Shangjia High-tech Materials Co., Ltd.; Knorr Vehicle Equipment Co., Ltd.; CRRC Qishuyan Locomotive Co., Ltd.; Changsha Boke Metal Products Co., Ltd. were respectively represented by suppliers 1-4. Fifty-two 
EMU depots: Hongqiao, Nanjing South, Nanxiang, Shanghai South, Hangzhou East, Hefei South, Nanjing, Guangzhou South, Shenzhen North, Changsha South, Huizhou, Guangzhou East, Foshan Xike, Foshan West, Changzhutan, Guangzhu, Sanya, Beijing South, Tianjin, Shijiazhuang, Beijing West, Beijing, Xiamen North, Fuzhou South, Nanchang West, Fuzhou, Nanchang, Longyan, Shenyang North, Dalian North, Shenyang South, Changchun West, Chengdu East, Guiyang North, Chongqing North, Wuhan, Hankou, Jinan, Qingdao North, Qingdao, Nanning, Guilin, Harbin West, Xi'an North, Zhengzhou East, Zhengzhou, Taiyuan South, Kunming South, Urumqi, Lanzhou West, Xining, Hohhot were respectively represented by DC 1-52 and Depot 1-52. See Tables 5 and 6 for detailed allocation.

Table 5. Situations of suppliers serving distribution centers.

\begin{tabular}{ll}
\hline Suppliers & Served Distribution Centers and Transportation Mode \\
\hline Supplier 1 & DC19 by air, DC20 by high-speed rail, DC21 by high-speed rail, DC44 by high-speed rail \\
Supplier 2 & DC1 by air, DC2 by highway, DC5 by highway, DC35 by highway, DC51 by high-speed rail \\
Supplier 3 & DC7 by air, DC13 by high-speed rail, DC40 by high-speed rail, DC43 by highway \\
Supplier 4 & $\begin{array}{l}\text { DC10 by high-speed rail, DC15 by high-speed rail, DC18 by highway, DC25 by highway, } \\
\text { DC26 by highway, DC39 by high-speed rail, DC41 by highway, DC47 by high-speed rail }\end{array}$ \\
\hline
\end{tabular}

Table 6. Situations of distribution centers serving EMU depots.

\begin{tabular}{ll}
\hline Selected Distribution Center & Served EMU Depots \\
\hline DC1 & Depot 11 by high-speed rail, Depot 22 by highway, Depot 49 by highway \\
DC2 & Depot 23 by air, Depot 32 by highway \\
DC5 & Depot 4 by high-speed rail, Depot 12 by highway \\
DC7 & Depot 3 by highway, Depot 9 by air \\
DC10 & Depot 14 by high-speed rail \\
DC13 & Depot 29 by high-speed rail \\
DC15 & Depot 34 by highway, Depot 45 by air \\
DC18 & Depot 38 by high-speed rail \\
DC19 & Depot 37 by highway \\
DC20 & Depot 52 by air \\
DC21 & Depot 27 by high-speed rail, Depot 33 by highway \\
DC25 & Depot 24 by high-speed rail \\
DC26 & Depot 8 by highway \\
DC35 & Depot 42 by highway \\
DC39 & Depot 28 by air, Depot 30 by highway \\
DC40 & Depot 48 by highway \\
DC41 & Depot 6 by highway, Depot 36 by highway \\
DC43 & Depot 16 by highway, Depot 31 by high-speed rail \\
DC44 & Depot 17 by highway, Depot 46 by air, Depot 50 by air \\
DC47 & \\
DC51 & \\
\hline
\end{tabular}

According to the results of Tables 5 and 6 , in the first stage from a supplier to a distribution center, because shipment sizes were large and the distances were long, the road transportation mode was selected 10 times, followed by the high-speed rail transportation mode eight times, and the air transportation mode was selected the least, three times. In the second stage, from a distribution center to an EMU depot, there were fewer shipment sizes. Even if the distance was long, the road was selected more often than the high-speed railway.

From the perspective of the total cost, Figure 8 shows that the proportion of the fixed operating cost (FC) account was the largest, which was $53.44 \%$, followed by the penalty cost (PC), which was $22.37 \%$, and the transportation cost (TC) and inventory cost (IC), which were $21.11 \%$ and $3.08 \%$, respectively. It can be seen that with the exception of the fixed operating costs, the penalty costs caused by stock shortages were the largest. Next, we will discuss the parameters related to the stock shortage cost. 


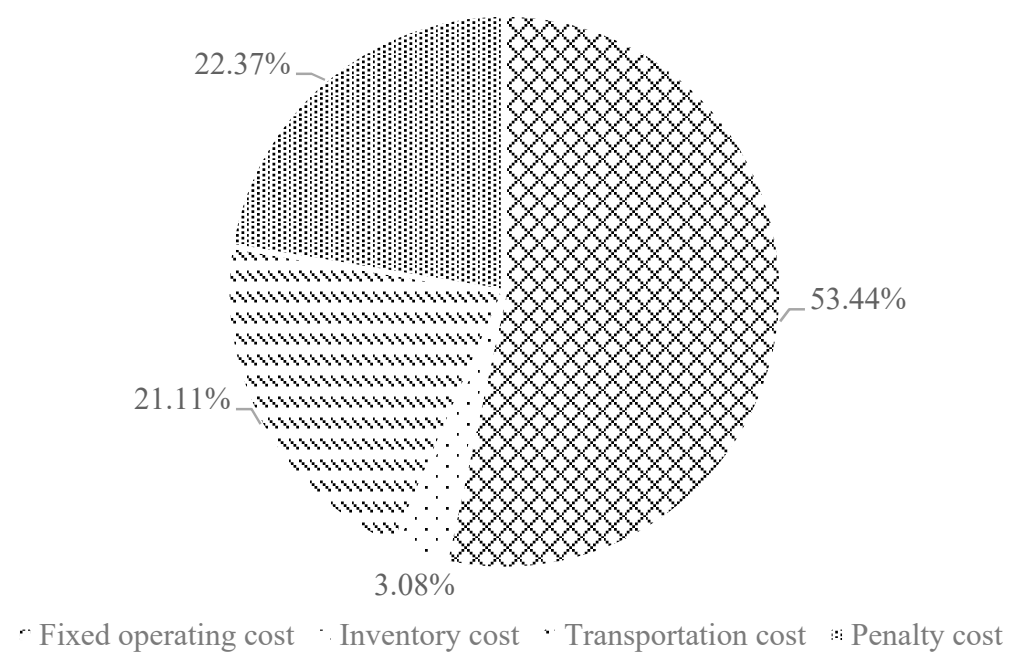

Figure 8. Proportion of each cost component.

\subsection{Discussion}

\subsubsection{Impact of Service Level for Total Cost and Transportation Mode}

To explore the impact of penalty costs on total costs and modes of transportation, this section used service levels as variables to derive management decisions about the impact of changing service levels on decisions. Then, we focused on how transportation mode decisions were subject to different service levels for each DC and EMU deport.

Figure 9 shows the optimal solution for the model at different service levels. As the service level increased, the total cost first decreased and then increased. The service level at the lowest total cost of the model was $95 \%$.

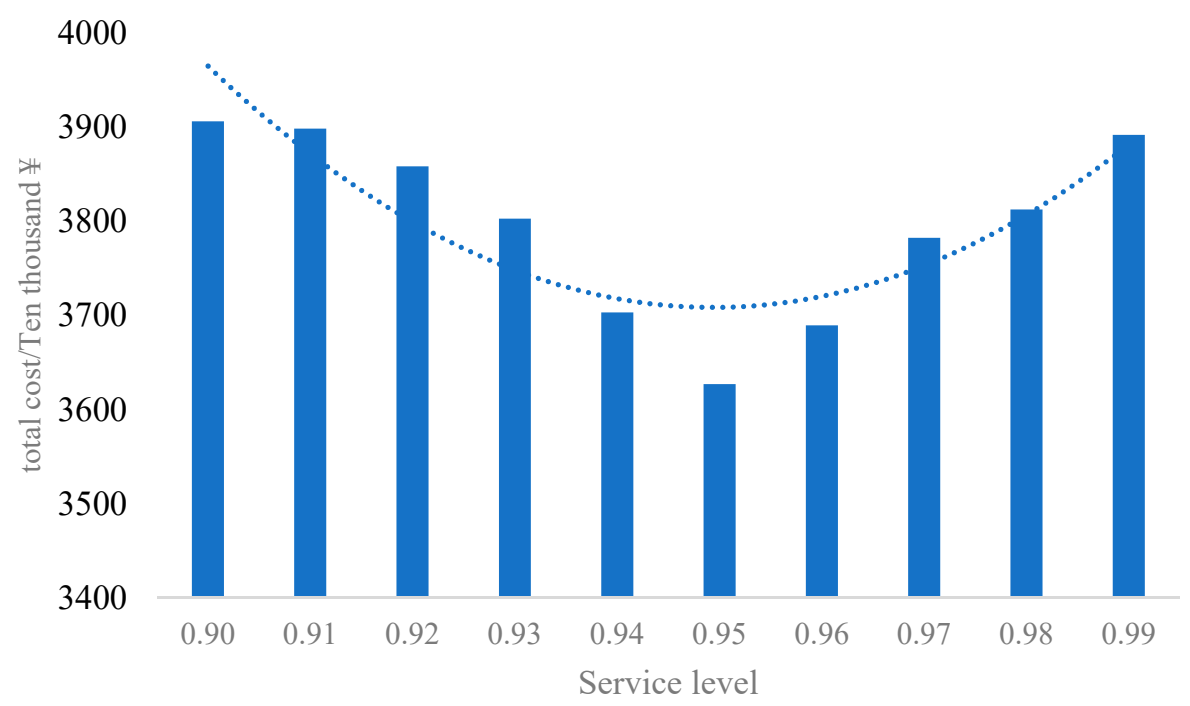

Figure 9. Sensitivity of total cost changes at different service levels.

Combining Table 7 with Figure 10, in the first stage from a supplier to a distribution center, the proportions of choosing air and high-speed rail transportation modes increased slightly, while the proportion of road transportation gradually decreased.

Table 7 and Figure 11 show that in the second stage from a distribution center to an EMU depot, because of the medium distances, the high-speed rail transportation mode was faster than the road, 
the cost was lower than the air mode, the advantages appeared, the proportions of the air and road transportation modes gradually decreased, and the proportion of the high-speed rail transportation mode gradually increased. However, the inexpensive road transportation mode still accounted for approximately half.

Table 7. Proportions of different transport modes at different service levels.

\begin{tabular}{|c|c|c|c|c|c|c|}
\hline \multirow[t]{2}{*}{ Service Level } & \multicolumn{3}{|c|}{ S-DC Echelon } & \multicolumn{3}{|c|}{ DC-E Echelon } \\
\hline & $\begin{array}{c}\text { Proportion of } \\
\text { Air } \\
\text { Transportation }\end{array}$ & $\begin{array}{l}\text { Proportion of } \\
\text { High-Speed Rail } \\
\text { Transportation }\end{array}$ & $\begin{array}{l}\text { Proportion of } \\
\text { Road } \\
\text { Transportation }\end{array}$ & $\begin{array}{l}\text { Proportion } \\
\text { of Air } \\
\text { Transportation }\end{array}$ & $\begin{array}{l}\text { Proportion of } \\
\text { High-Speed Rail } \\
\text { Transportation }\end{array}$ & $\begin{array}{c}\text { Proportion of } \\
\text { Road } \\
\text { Transportation }\end{array}$ \\
\hline 0.90 & $11.5 \%$ & $23.1 \%$ & $65.4 \%$ & $25.0 \%$ & $19.2 \%$ & $55.8 \%$ \\
\hline 0.91 & $17.4 \%$ & $30.4 \%$ & $52.2 \%$ & $21.2 \%$ & $13.5 \%$ & $65.4 \%$ \\
\hline 0.92 & $19.2 \%$ & $30.8 \%$ & $50.0 \%$ & $25.0 \%$ & $26.9 \%$ & $48.1 \%$ \\
\hline 0.93 & $14.3 \%$ & $38.1 \%$ & $47.6 \%$ & $15.4 \%$ & $30.8 \%$ & $53.8 \%$ \\
\hline 0.94 & $21.1 \%$ & $31.6 \%$ & $47.4 \%$ & $17.3 \%$ & $25.0 \%$ & $57.7 \%$ \\
\hline 0.95 & $18.2 \%$ & $31.8 \%$ & $50.0 \%$ & $13.5 \%$ & $34.6 \%$ & $51.9 \%$ \\
\hline 0.96 & $12.5 \%$ & $33.3 \%$ & $54.2 \%$ & $26.9 \%$ & $30.8 \%$ & $42.3 \%$ \\
\hline 0.97 & $20.0 \%$ & $28.0 \%$ & $52.0 \%$ & $19.2 \%$ & $23.1 \%$ & $57.7 \%$ \\
\hline 0.98 & $17.4 \%$ & $26.1 \%$ & $56.5 \%$ & $13.5 \%$ & $34.6 \%$ & $51.9 \%$ \\
\hline 0.99 & $17.4 \%$ & $34.8 \%$ & $47.8 \%$ & $15.4 \%$ & $34.6 \%$ & $50.0 \%$ \\
\hline
\end{tabular}

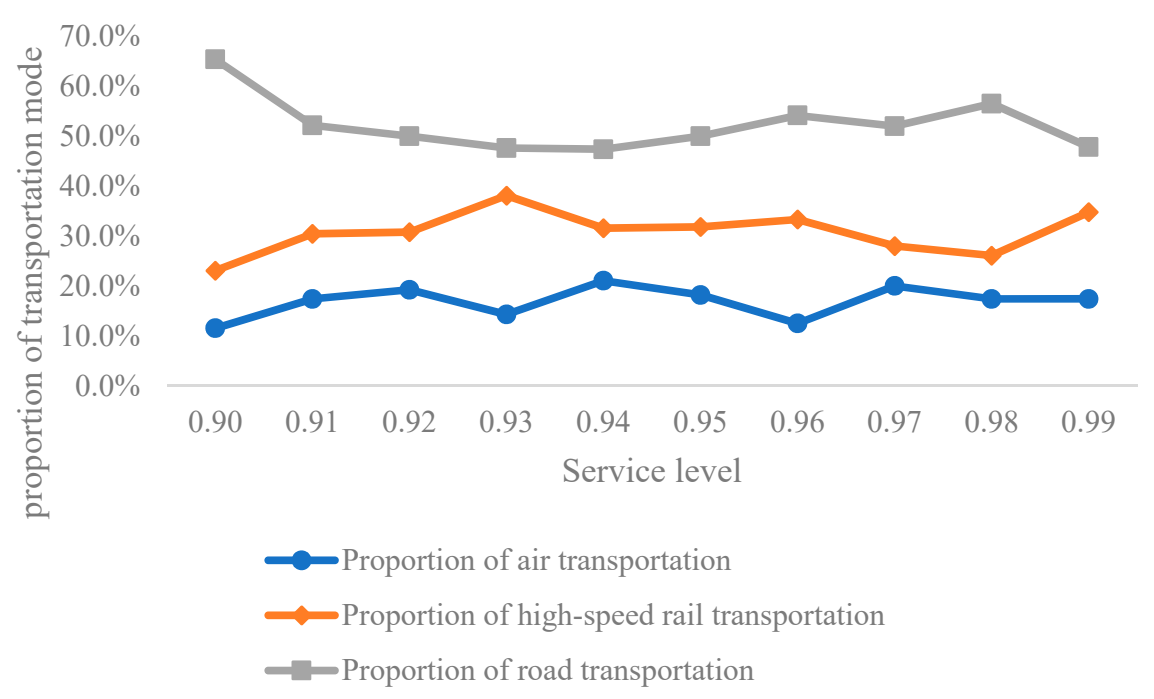

Figure 10. Proportions of transportation modes in the S-DC stage at different service levels.

The findings show that (i) adjusting the service level can achieve the purpose of reducing the total cost of the distribution network, but the concept of safety first does not apply to the inventory, and the higher service level is not better. Although the higher the service level is, the smaller the stockout cost, the transportation cost is higher. (ii) In addition to changing the shipment size and allocation situation, it is feasible for the China Railway Administration to appropriately adjust the transportation mode in the maintenance component distribution network. When choosing the ratio of air, high-speed rail, and road transportation as approximately 2:3:5, the total cost is the smallest.

\subsubsection{Impact of Unit Stockout Cost on Total Cost and Transportation Mode}

To explore the impact of unit stockout cost on the total cost and the choice of transportation method, we performed a simulation analysis to study the sensitivity of the cost to changes in different service levels and unfulfilled demand costs. Assume that the stockout costs are $0.4,0.7$, and $1.0 \times ¥ 10,000$, respectively. The results are shown in Figure 12. 


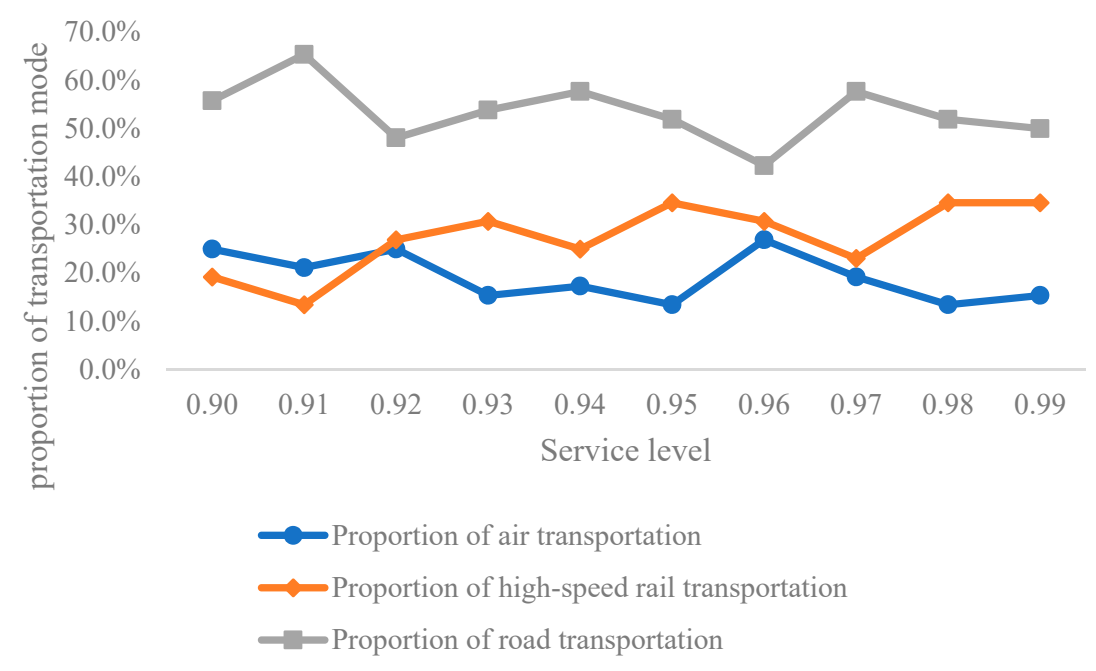

Figure 11. Proportions of transportation modes in the DC-E stage at different service levels.

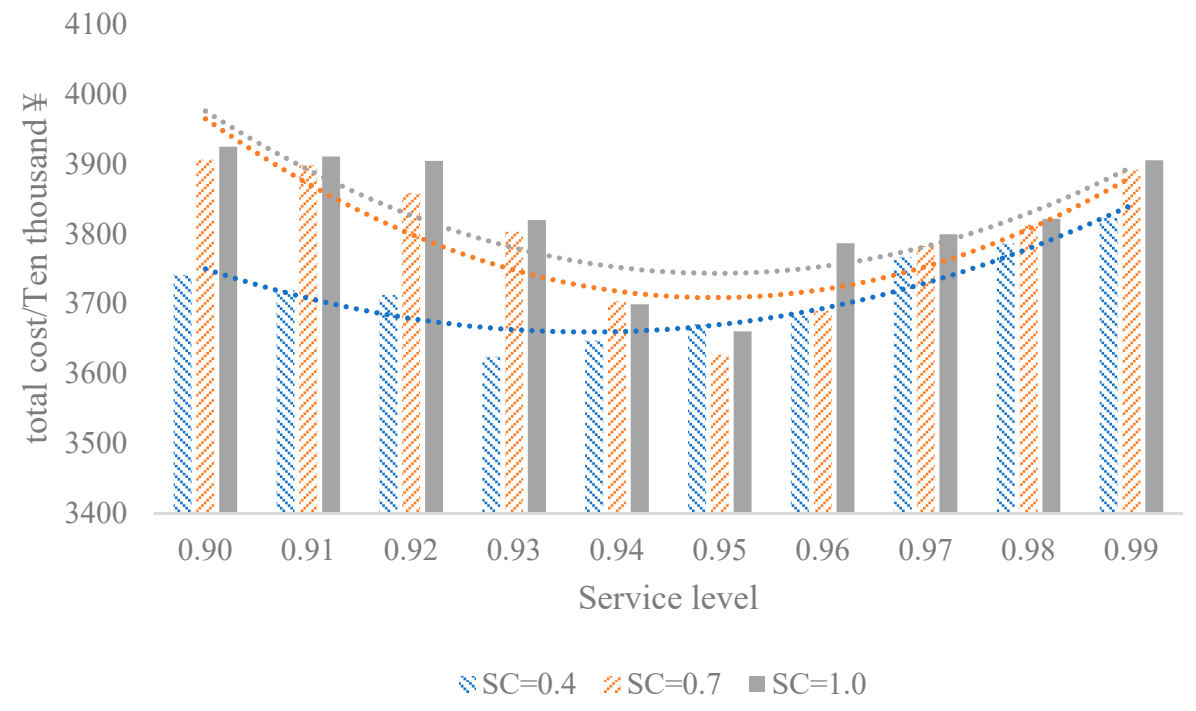

Figure 12. Sensitivity of cost to changes in different service levels and unit unfulfilled demand costs.

As we expected, Figure 12 shows that the optimal service level increased with increasing unit stockout cost. When the stockout cost was 0.4 , the optimal service level was 0.93 . When the unit stockout costs were 0.7 and 1.0, the best service level was 0.95 .

Except for changes in total cost, we analyzed the proportions of different transportation modes at the optimal service level for different stockout costs.

Table 8 and Figure 13 show that with the increase in the unit stockout cost, in the first stage, the proportion of choosing aircraft transportation increased greatly. Although the proportions of both high-speed rail and road transportation modes declined, the decreased proportion of the latter was greater than that of the former. This implies that the operator of China High-Speed Railway would rather choose air transportation with expensive transport costs and ordering costs than high-speed rail or road transportation if there existed a higher cost of out-of-stock maintenance components because the penalty cost on the out-of-stock cost was much more than the total of the above two costs (i.e., transport cost and ordering cost).

Table 8 and Figure 14 show that, in the second stage, the proportions of transportation modes did not change significantly. Consistent with the conclusions reached in Section 5.2.1, the air, high-speed 
rail, and road transportation methods remained at a ratio of 2:3:5, respectively, with minimal total cost. However, when the maintenance components reached the DC, the distances from DC to the EMU depot served were not far and the demand batch was not large, the impact of the unit shortage cost was less than that of the transportation cost and the order cost. Therefore, when the unit shortage cost changed, the proportions of the different transportation modes had fewer changes.

Table 8. Proportions of different transport modes at different shortage costs (SCs).

\begin{tabular}{|c|c|c|c|c|c|c|}
\hline & \multicolumn{3}{|c|}{ S-DC Echelon } & \multicolumn{3}{|c|}{ DC-E Echelon } \\
\hline $\mathrm{SC}=0.4$ & $4.6 \%$ & $31.8 \%$ & $63.6 \%$ & $13.5 \%$ & $30.8 \%$ & $55.8 \%$ \\
\hline $\mathrm{SC}=0.7$ & $18.2 \%$ & $31.8 \%$ & $50.0 \%$ & $13.5 \%$ & $34.6 \%$ & $51.9 \%$ \\
\hline $\mathrm{SC}=1.0$ & $28.0 \%$ & $24.0 \%$ & $48.0 \%$ & $19.2 \%$ & $30.8 \%$ & $50.0 \%$ \\
\hline
\end{tabular}

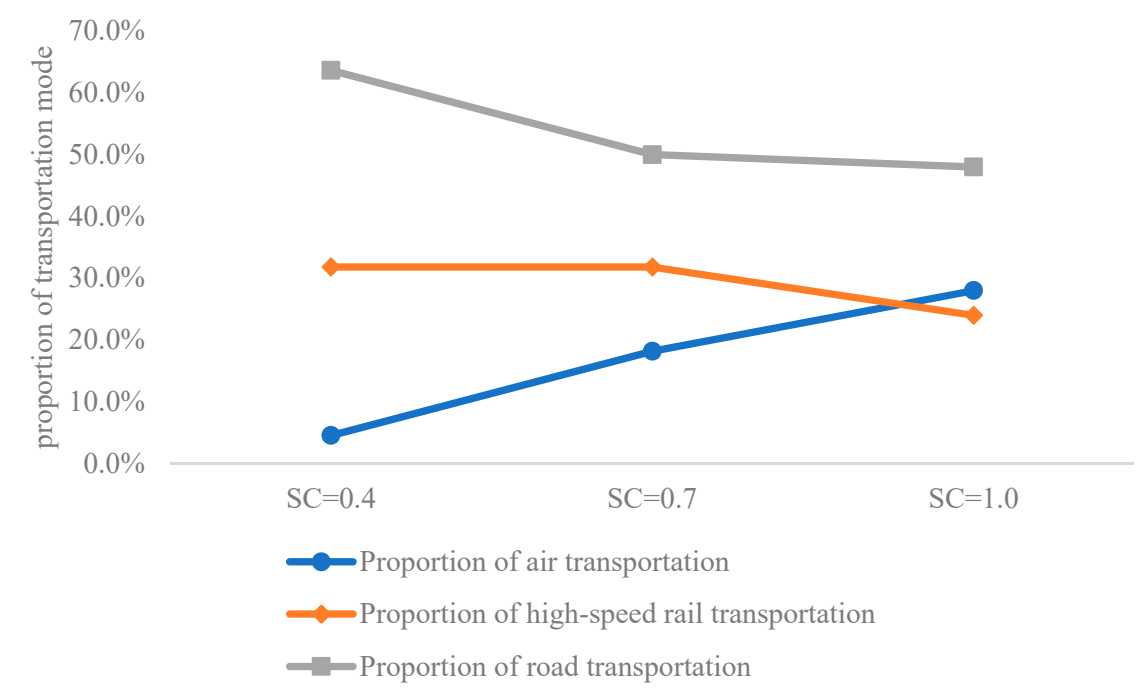

Figure 13. Proportions of transportation modes in the S-DC stage at different shortage costs.

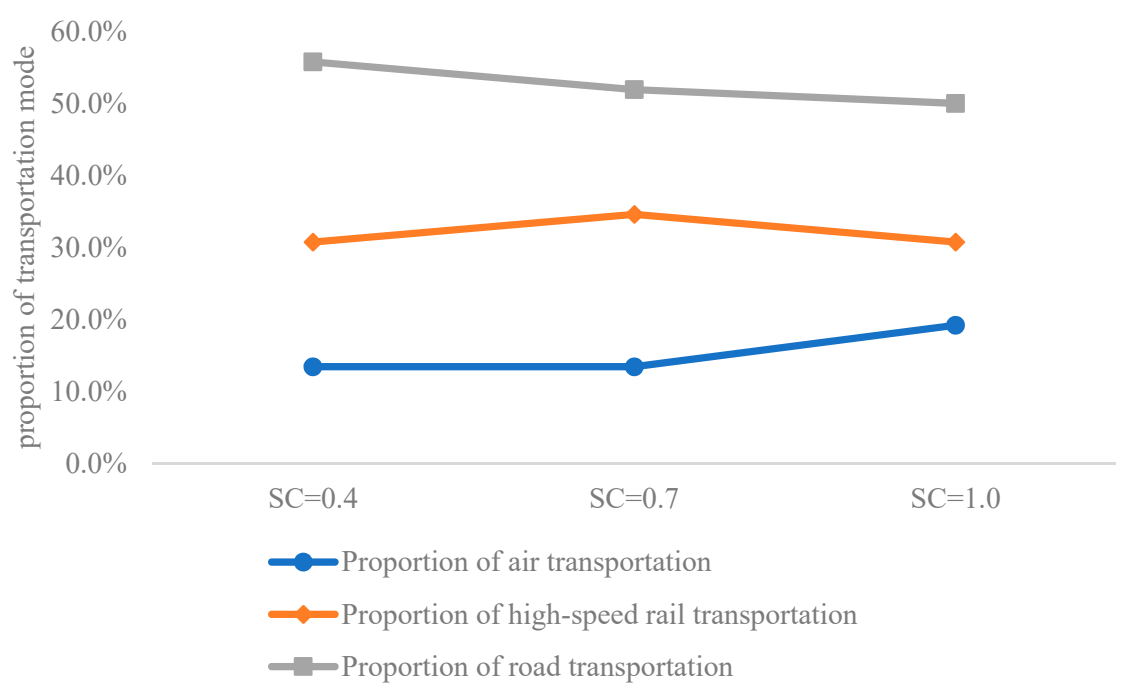

Figure 14. Proportions of transportation modes in the DC-E stage at different shortage costs. 
The findings show that (i) there is a correlation between unit stockout cost and optimal service level. The higher the stockout cost is, the higher the optimal service level, the greater the proportion of air transportation options with high transportation costs and high order costs. (ii) Even at the optimal service level, the higher the unit stockout cost is, the larger the proportion of choosing expensive and fast transportation methods. The China Railway Administration can improve the supply chain. If a low stockout cost is set, the total cost can be reduced by reducing the optimal service level.

\section{Conclusions and Future Work}

This paper addressed an integrated optimization model of the location-inventory problem for EMU component distribution that incorporates the location cost of a DC, the inventory cost, the linear transportation cost from the distribution center to the EMU depot, and the penalty cost. The proposed problem needed to solve the following three key questions: (i) the number and locations of distribution centers; (ii) the allocations from suppliers to the distribution centers and from the distribution centers to the EMU depots, and the choice of transportation modes; and (iii) the distribution center optimal order quantity, reorder point, and safety stock.

To solve the above optimal model, an adaptive genetic algorithm was given. The performance of the proposed adaptive genetic algorithm was evaluated by comparing it with a standard genetic algorithm. Moreover, a real-world case study based on the EMU maintenance component distribution network design of the China High-Speed Railway was employed to verify the effectiveness of the above optimization model and its algorithm.

The main management insights of this study are shown as follows: (i) The higher service level is not necessarily the better, although the higher the service level is, the smaller the stockout cost, but the transportation cost is higher. When higher service levels are required, faster transportation methods are needed, so the cost of the entire supply chain will rise. (ii) In addition to the optimal service level, the China Railway Administration must determine the unit stockout cost; the higher the unit stockout cost is, the larger the proportion of choosing expensive and fast transportation methods. (iii) It is reasonable to choose the mode of transportation and set the proportions of transportation modes. Air, high-speed rail, and road transportation modes are optimal at a ratio of 2:3:5.

Although we used our best efforts to reflect the actual situation of the EMU maintenance component distribution network design, in order to facilitate the theoretical solution we simplified it appropriately. There are many extensions that should be studied in the future. First, we hope to develop the cases with multiple items. The China Railway high-speed train has nine types of body models composed of more than 140 systems and approximately 40,000 parts. Second, we would like to consider the problem of location inventory transportation and make strategic, tactical, and operational decisions simultaneously. This needs to take into account the schedule of various modes of transportation or vehicle routing problems. Moreover, we need to combine the actual situation, considering the sharing of maintenance components between railway bureaus. Finally we would like to improve the performance of the AGA by embedding with other heuristic algorithms (e.g., tabu search, local search, simulated annealing) and to investigate more comparison or benchmarking instances in the future studies.

Author Contributions: Conceptualization, D.Z. and S.Y.; methodology, D.Z., S.Y. and B.J.; investigation, S.Y., S.L. and J.F.; writing-original draft preparation, S.Y. and J.F.; writing-review and editing, D.Z., B.J. and S.L.; supervision, D.Z., B.J. and S.L.; funding acquisition, D.Z., B.J. and S.L. All authors have read and agreed to the published version of the manuscript.

Funding: This research was funded by the National Natural Science Foundation of China, grant numbers 71672193 and 71371181 .

Acknowledgments: We would like to express our deep gratitude for the joint support by the National Natural Science Foundation of China (No. 71672193 and 71371181), and the Graduate education reform project of Central South University (No. 2018JG13).

Conflicts of Interest: The authors declare no conflict of interest. 


\section{References}

1. Wang, K.; Xia, W.; Zhang, A. Should China further expand its high-speed rail network? Consider the low-cost carrier factor. Transp. Res. Part A Policy Pract. 2017, 100, 105-120. [CrossRef]

2. Zhang, Q.; Yang, H.; Wang, Q.; Zhang, A.; Zhang, Y. Impact of high-speed rail on market concentration and Lerner index in China's airline market. J. Air Transp. Manag. 2020, 83, 101755. [CrossRef]

3. Zhu, Z.; Zhang, A.; Zhang, Y. Connectivity of intercity passenger transportation in China: A multi-modal and network approach. J. Transp. Geogr. 2018, 71, 263-276. [CrossRef]

4. Lin, B.; Wang, J.; Wang, H.; Wang, Z.; Li, J.; Lin, R.; Xiao, J.; Wu, J. Inventory-transportation integrated optimization for maintenance spare parts of high-speed trains. PLoS ONE 2017, 12, e176961. [CrossRef] [PubMed]

5. Zokaee, S.; Jabbarzadeh, A.; Fahimnia, B.; Sadjadi, S. Robust supply chain network design: An optimization model with real world application. Ann. Oper. Res. 2017, 257, 15-44. [CrossRef]

6. Owen, S.H.; Daskin, M.S. Strategic facility location: A review. Eur. J. Oper. Res. 1998, 111, 423-447. [CrossRef]

7. Cordeau, J.; Furini, F.; Ljubić, I. Benders decomposition for very large scale partial set covering and maximal covering location problems. Eur. J. Oper. Res. 2019, 275, 882-896. [CrossRef]

8. Hakli, H.; Ortacay, Z. An improved scatter search algorithm for the uncapacitated facility location problem. Comput. Ind. Eng. 2019, 135, 855-867. [CrossRef]

9. Kınay, Ö.B.; Saldanha-da-Gama, F.; Kara, B.Y. On multi-criteria chance-constrained capacitated single-source discrete facility location problems. Omega 2019, 83, 107-122. [CrossRef]

10. Kratica, J.; Dugošija, D.; Savić, A. A new mixed integer linear programming model for the multi level uncapacitated facility location problem. Appl. Math. Model. 2014, 38, 2118-2129. [CrossRef]

11. Brotcorne, L.; Laporte, G.; Semet, F. Fast heuristics for large scale covering-location problems. Comput. Oper. Res. 2002, 29, 651-665. [CrossRef]

12. Davoodi, M. k-Balanced Center Location problem: A new multi-objective facility location problem. Comput. Oper. Res. 2019, 105, 68-84. [CrossRef]

13. Nasiri, M.M.; Mahmoodian, V.; Rahbari, A.; Farahmand, S. A modified genetic algorithm for the capacitated competitive facility location problem with the partial demand satisfaction. Comput. Ind. Eng. 2018, 124, 435-448. [CrossRef]

14. Ramshani, M.; Ostrowski, J.; Zhang, K.; Li, X. Two level uncapacitated facility location problem with disruptions. Comput. Ind. Eng. 2019, 137, 106089. [CrossRef]

15. Shen, Z.M. A multi-commodity supply chain design problem. IIE Trans. 2005, 37, 753-762. [CrossRef]

16. Merakl1, M.; Yaman, H. A capacitated hub location problem under hose demand uncertainty. Comput. Oper. Res. 2017, 88, 58-70. [CrossRef]

17. Correia, I.; Nickel, S.; Saldanha-da-Gama, F. A stochastic multi-period capacitated multiple allocation hub location problem: Formulation and inequalities. Omega 2018, 74, 122-134. [CrossRef]

18. Alumur, S.A.; Nickel, S.; Rohrbeck, B.; Saldanha-da-Gama, F. Modeling congestion and service time in hub location problems. Appl. Math. Model. 2018, 55, 13-32. [CrossRef]

19. Zeng, B.; Zhao, L. Solving two-stage robust optimization problems using a column-and-constraint generation method. Oper. Res. Lett. 2013, 41,457-461. [CrossRef]

20. Holmberg, K. Exact solution methods for uncapacitated location problems with convex transportation costs. Eur. J. Oper. Res. 1999, 114, 127-140. [CrossRef]

21. Barcelo, J.; Fernandez, E.; Jörnsten, K.O. Computational results from a new Lagrangean relaxation algorithm for the capacitated plant location problem. Eur. J. Oper. Res. 1991, 53, 38-45. [CrossRef]

22. Farahani, R.Z.; Hekmatfar, M.; Arabani, A.B.; Nikbakhsh, E. Hub location problems: A review of models, classification, solution techniques, and applications. Comput. Ind. Eng. 2013, 64, 1096-1109. [CrossRef]

23. Cheng, C.; Qi, M.; Zhang, Y.; Rousseau, L. A two-stage robust approach for the reliable logistics network design problem. Transp. Res. Part B Methodol. 2018, 111, 185-202. [CrossRef]

24. Jiang, J.; Zhang, D.; Meng, Q.; Liu, Y. Regional multimodal logistics network design considering demand uncertainty and CO2 emission reduction target: A system-optimization approach. J. Clean. Prod. 2020, 248, 119304. [CrossRef]

25. SteadieSeifi, M.; Dellaert, N.P.; Nuijten, W.; Van Woensel, T.; Raoufi, R. Multimodal freight transportation planning: A literature review. Eur. J. Oper. Res. 2014, 233, 1-15. [CrossRef] 
26. Alumur, S.A.; Nickel, S.; Saldanha-da-Gama, F. Hub location under uncertainty. Transp. Res. Part B Methodol. 2012, 46, 529-543. [CrossRef]

27. Habibi, M.K.K.; Allaoui, H.; Goncalves, G. Collaborative hub location problem under cost uncertainty. Comput. Ind. Eng. 2018, 124, 393-410. [CrossRef]

28. Nickel, S.; Reuter-Oppermann, M.; Saldanha-da-Gama, F. Ambulance location under stochastic demand: A sampling approach. Oper. Res. Health Care 2016, 8, 24-32. [CrossRef]

29. Saedinia, R.; Vahdani, B.; Etebari, F.; Afshar Nadjafi, B. Robust gasoline closed loop supply chain design with redistricting, service sharing and intra-district service transfer. Transp. Res. Part E Logist. Transp. Rev. 2019, 123, 121-141. [CrossRef]

30. Singh, A.K.; Subramanian, N.; Pawar, K.S.; Bai, R. Cold chain configuration design: Location-allocation decision-making using coordination, value deterioration, and big data approximation. Ann. Oper. Res. 2018, 270, 433-457. [CrossRef]

31. Miranda, P.A.; Garrido, R.A. Inventory service-level optimization within distribution network design problem. Int. J. Prod. Econ. 2009, 122, 276-285. [CrossRef]

32. Zhang, D.; Zhan, Q.; Chen, Y.; Li, S. Joint optimization of logistics infrastructure investments and subsidies in a regional logistics network with $\mathrm{CO} 2$ emission reduction targets. Transp. Res. Part D Transp. Environ. 2018, 60, 174-190. [CrossRef]

33. Daskin, M.S.; Coullard, C.R.; Shen, Z.M. An Inventory-Location Model: Formulation, Solution Algorithm and Computational Results. Ann. Oper. Res. 2002, 110, 83-106. [CrossRef]

34. Zuo-Jun, M.S.; Collette, C.; Mark, S.D. A Joint Location-Inventory Model. Transp. Sci. 2003, 37, 40-55.

35. Liao, S.; Hsieh, C.; Lai, P. An evolutionary approach for multi-objective optimization of the integrated location-inventory distribution network problem in vendor-managed inventory. Expert Syst. Appl. 2011, 38, 6768-6776. [CrossRef]

36. Silva, F.; Gao, L. A Joint Replenishment Inventory-Location Model. Netw. Spat. Econ. 2013, 13, 107-122. [CrossRef]

37. Araya-Sassi, C.; Miranda, P.A.; Paredes-Belmar, G. Lagrangian Relaxation for an Inventory Location Problem with Periodic Inventory Control and Stochastic Capacity Constraints. Math. Probl. Eng. 2018, 2018, 1-27. [CrossRef]

38. Wheatley, D.; Gzara, F.; Jewkes, E. Logic-based Benders decomposition for an inventory-location problem with service constraints. Omega 2015, 55, 10-23. [CrossRef]

39. Jahangir, H.; Mohammadi, M.; Pasandideh, S.H.R.; Nobari, N.Z. Comparing performance of genetic and discrete invasive weed optimization algorithms for solving the inventory routing problem with an incremental delivery. J. Intell Manuf. 2019, 30, 2327-2353. [CrossRef]

40. Liu, Y.; Dehghani, E.; Jabalameli, M.S.; Diabat, A.; Lu, C. A coordinated location-inventory problem with supply disruptions: A two-phase queuing theory-optimization model approach. Comput. Ind. Eng. 2020, 142, 106326. [CrossRef]

41. Setak, M.; Feizizadeh, F.; Tikani, H.; Ardakani, E.S. A bi-level stochastic optimization model for reliable supply chain in competitive environments: Hybridizing exact method and genetic algorithm. Appl. Math. Model. 2019, 75, 310-332. [CrossRef]

42. Biuki, M.; Kazemi, A.; Alinezhad, A. An integrated location-routing-inventory model for sustainable design of a perishable products supply chain network. J. Clean. Prod. 2020, 260, 120842. [CrossRef]

43. Dai, Z.; Aqlan, F.; Zheng, X.; Gao, K. A location-inventory supply chain network model using two heuristic algorithms for perishable products with fuzzy constraints. Comput. Ind. Eng. 2018, 119, 338-352. [CrossRef]

44. Gu, J.; Zhang, G.; Li, K.W. Efficient aircraft spare parts inventory management under demand uncertainty. J. Air Transp. Manag. 2015, 42, 101-109. [CrossRef]

45. Vahdani, B.; Soltani, M.; Yazdani, M.; Meysam Mousavi, S. A three level joint location-inventory problem with correlated demand, shortages and periodic review system: Robust meta-heuristics. Comput. Ind. Eng. 2017, 109, 113-129. [CrossRef]

46. Farahani, R.Z.; Rashidi Bajgan, H.; Fahimnia, B.; Kaviani, M. Location-inventory problem in supply chains: A modelling review. Int. J. Prod. Res. 2014, 53, 3769-3788. [CrossRef]

47. Manatkar, R.P.; Karthik, K.; Kumar, S.K.; Tiwari, M.K. An integrated inventory optimization model for facility location-allocation problem. Int. J. Prod. Res. 2016, 54, 3640-3658. [CrossRef] 
48. Shahabi, M.; Unnikrishnan, A.; Jafari-Shirazi, E.; Boyles, S.D. A three level location-inventory problem with correlated demand. Transp. Res. Part B Methodol. 2014, 69, 1-18. [CrossRef]

49. Ahmadi-Javid, A.; Hoseinpour, P. Incorporating location, inventory and price decisions into a supply chain distribution network design problem. Comput. Oper. Res. 2015, 56, 110-119. [CrossRef]

50. Srinivas, M.; Patnaik, L.M. Adaptive probabilities of crossover and mutation in genetic algorithms. IEEE Trans. Syst. ManCybern. 1994, 24, 656-667. [CrossRef]

(C) 2020 by the authors. Licensee MDPI, Basel, Switzerland. This article is an open access article distributed under the terms and conditions of the Creative Commons Attribution (CC BY) license (http://creativecommons.org/licenses/by/4.0/). 